\title{
Brachial pulse pressure is associated with the presence and extent of coronary artery disease in stable angina patients: a cross-sectional study
}

Jin $\mathrm{Li}^{\dagger}$, Yangpei Peng ${ }^{\dagger}$ and Kangting $\mathrm{Ji}^{*}$

\begin{abstract}
Background: Previous epidemiological evidence has identified many risk factors for coronary artery disease (CAD). Pulse pressure (PP) was reported to be associated with CAD. However, more attention was paid to aortic PP than to brachial PP. This cross-sectional study aimed to investigate the direct relationship between brachial PP and the presence and extent of CAD in stable angina patients.

Methods: We recruited a total of 1118 consecutive patients with stable chest pain suspected of CAD. After screening with exclusion criteria, 654 patients were finally included in our study. Every patient underwent both blood pressure measurement and selective coronary angiography. Univariate and multivariate analysis were performed to analyze the association between PP and the presence and extent of CAD.

Results: This study revealed that brachial PP was an independent correlate of multivessel CAD. In multivariate generalized linear regression model, increasing brachial PP (per $1 \mathrm{mmHg}$ ) were associated with the increased number of diseased vessels $(\beta=0.01, S E=0.00, P<0.0001)$. Binary logistic regression analysis further confirmed this association. The risk of multivessel $C A D$ increased significantly in patients with brachial $P P \geq 60 \mathrm{mmHg}(\mathrm{OR}=1.69$, $95 \% \mathrm{Cl}=1.14-2.48, P=0.0084)$ and as per $1 \mathrm{mmHg}$ increased in brachial $\mathrm{PP}(\mathrm{OR}=1.02,95 \% \mathrm{Cl}=1.01-1.03, P=$ 0.0002), independent of age, gender, body mass index (BMI), smoking, diabetes, hypercholesterolemia and creatinine (Cr). This association was still of statistical significance in subgroup analysis of hypertension and diabetes.

Conclusion: Increasing brachial PP was significantly and independently associated with increased risk of multivessel coronary disease in stable angina patients. The association of brachial PP with CAD was more pronounced in hypertension group than in non-hypertension one.
\end{abstract}

Keywords: Brachial pulse pressure, Coronary artery disease, Stable angina

\footnotetext{
* Correspondence: jikt@wzmc.edu.cn

${ }^{\dagger}$ Jin Li and Yangpei Peng contributed equally to this work. Department of Cardiology, The Second Affiliated Hospital of Wenzhou Medical University, Wenzhou 325000, Zhejiang, China
} 


\section{Background}

Coronary artery disease (CAD) is the leading cause of death worldwide [1,2]. Given the high morbidity and mortality of CAD, its early diagnosis and prevention have attracted the attention of medical workers. Epidemiological evidence has identified many risk factors for CAD. Pulse pressure (PP), defined as the difference between systolic and diastolic blood pressure (SBP and DBP), has also been declared to be associated with CAD. Increased PP was shown to be related to arterial stiffness [3-5] and adverse cardiovascular events [6-9]. Several studies have investigated the association between PP and the extent of CAD in patients undergoing invasive coronary angiography (CAG). Their main focus, however, was aortic pressure, not brachial pressure [10-13]. Brachial PP, as a non-invasive and easily available indicator, can be better applied in clinical practice. Therefore, in this cross-sectional study, we explored the relationship between brachial PP and the presence and extent of coronary artery disease in the stable angina patients.

\section{Methods}

\section{Study population}

From December 2012 to February 2014, we consecutively recruited 1108 patients with stable chest pain suspected of CAD undergoing selective CAG. We excluded those with unstable angina, non-ST segment elevation myocardial infarction, ST-segment elevation myocardial infarction, previously coronary angiographically confirmed CAD or a history of revascularization (241). Patients with any of the following conditions were also excluded: treated with medications affecting blood pressure (BP) within 12 months (eg, calcium channel blockers, $\beta$-blockers, angiotensin-converting enzyme inhibitors, etc.) (94); a history of heart failure with a left ventricular ejection fraction (LVEF) less than $50 \%$ (68); renal failure (36), thyroid diseases (12), or incorrect BP measurements or reports (3). A total of 654 patients were finally included in our study (Fig. 1).

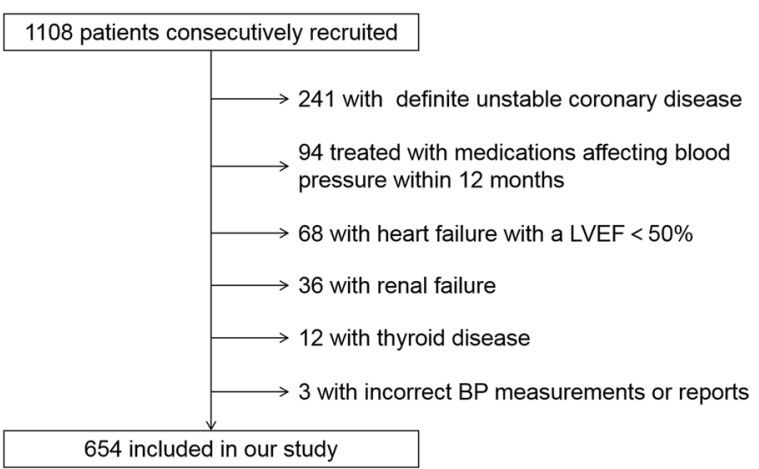

Fig. 1 Flow chart of the population included in the study
To obtain the required information, every individual received standardized interviews and basic checks prior to the CAG. Body mass index (BMI) was calculated by dividing weight $(\mathrm{kg})$ by height $\left(\mathrm{m}^{2}\right)$. Smoking status depended on self-report. Diabetes was defined as fasting blood glucose $\geq 7.1 \mathrm{mmol} / \mathrm{L}$ and/or random blood glucose $\geq 11.1 \mathrm{mmol} / \mathrm{L}$ and/or receiving hypoglycemic treatment. Hypercholesterolemia was defined as total cholesterol $\geq 5.72 \mathrm{mmol} / \mathrm{L}$ and/or low-density lipoprotein cholesterol $\geq 3.64 \mathrm{mmol} / \mathrm{L}$ and/or receiving lipid-lowering treatment. Serum creatinine $(\mathrm{Cr})$ was determined by the biochemical analyzer and expressed in $\mu \mathrm{mol} / \mathrm{L}$. Hypertension was defined on the basis of previous diagnoses and also the two BP measurements taken during the study ( $\mathrm{SBP} \geq 140 \mathrm{mmHg}$ and/or $\mathrm{DBP} \geq 90 \mathrm{mmHg}$ ).

This study conformed to the Declaration of Helsinki and was approved by the institutional review committee of Wenzhou Medical University. We obtained the written informed consent of each enrolled patient.

\section{Coronary angiography}

All patients underwent CAG examination by standard Judkin's techniques. Visual analyses were applied to assess the percentage of coronary lumen diameter stenosis. CAD was defined as a $50 \%$ luminal diameter stenosis of a major epicardial artery or the left main coronary artery. Multivessel CAD was defined as a $50 \%$ luminal diameter stenosis in at least two major epicardial vessels or the left main coronary artery.

The coronary angiograms were reviewed by two experienced cardiologists who were blinded to the results of brachial PP.

\section{Brachial PP calculation}

PP was defined as the difference between SBP and DBP. Brachial BP was measured on the basis of internationally accepted standard measurements. The brachial BP was measured within $24 \mathrm{~h}$ on patient's first admission. We used the calibrated mercury sphygmomanometer and the strips manchet of right size. Before measuring BP, smoking or drinking coffee was prohibited within $30 \mathrm{~min}$. Also, patients should empty the bladder and sit quietly for at least $5 \mathrm{~min}$. When measuring BP, patients were asked in sitting position with bare upper arm at heart level. If peripheral vascular disease was suspected, the BP was measured both on the left and right upper arm and the higher reading was recorded. BP was expressed in millimeter of mercury (mmHg). Measurements were repeated 1 to 2 min apart and the average of two readings was recorded. If two readings of SBP or DBP differed by more than 5 $\mathrm{mmHg}$, the BP then was remeasured and the average of the three readings was recorded. 


\section{Statistical analysis}

Continuous data were expressed as mean and standard deviation (SD), while discrete data as numbers and percentages. Continuous data were compared by the variance analysis or the Kruskal-Wallis test, while discrete data by the chi-square test [14] or Fisher's exact test [15].

Univariate and multivariate generalized linear regression analyses were used to determine the relationship between brachial PP and the number of diseased vessels. Confounders were selected on the basis of their relevance to the outcome or the presence of more than $10 \%$ mutations in effect estimate or $P$ values $<0.1$. Multivariate logistic regression analyses were applied to investigate the relationship between brachial PP and the multivessel CAD. Subgroup analyses were performed to further explore the relationship between brachial PP and CAD.

For missing of covariates (BMI was missing 93; Cr was missing 86), we used multiple multivariate imputations. Our purpose was to maximize statistical power and minimize bias caused by excluding covariates of missing data in data analysis. In addition, we used sensitivity analysis to identify whether created complete data had significant difference from pre-imputation data. Our findings demonstrated that created complete data showed no significant difference from raw data.

We regarded a $P$ value $<0.05$ as of statistical significance. EmpowerStats version 2.17.8 (http://www.empowerstats.com/cn/) and R software (http://www.R-project. org) were used for statistical analysis in our study.

\section{Results}

Baseline characteristics

Patient demographics are presented in Table 1. Among the 654 subjects included, 374 were classified as CAD and 280 as non-CAD. The patients were stratified according to the number of diseased coronary vessels $(0$, 1,2 , and 3). And patients with 0 -vessel disease are the controls. There were significant differences for age, gender, smoking, diabetes, and $\mathrm{Cr}$ across the four groups, while no significant differences for BMI and hypercholesterolemia. For BP, significant differences were observed in hypertension, SBP and PP, but not in DBP, as the number of diseased coronary vessels increased.

\section{Association between brachial PP and CAD}

Both univariate and multivariate analysis were used to analyze the relationship between the brachial PP and the number of diseased vessels. Increasing brachial PP (per $1 \mathrm{mmHg}$ ) were associated with the increased number of diseased vessels $(\beta=0.01$, SE $=0.00, P<0.0001)$, after adjusted for age, gender, BMI, smoking, diabetes, hypercholesterolemia and $\mathrm{Cr}$. This association was also observed when patients divided into non-hypertension and hypertension (Table 2).

Of the 654 symptomatic patients, 203 (31.04\%) had multivessel CAD (luminal stenosis $\geq 50 \%$ in two or more vessels). Among the included patients, the risk of multivessel CAD increased significantly in patients with brachial $\mathrm{PP} \geq 60 \mathrm{mmHg}(\mathrm{OR}=1.69,95 \% \mathrm{CI}=1.14-2.48, P=$ $0.0084)$ and as per $1 \mathrm{mmHg}$ increased in brachial PP $(\mathrm{OR}=1.02,95 \% \mathrm{CI}=1.01-1.03, P=0.0002)$, independent of age, gender, BMI, smoking, diabetes, hypercholesterolemia and $\mathrm{Cr}$ (Table 3). In subgroup analysis, the increased adjusted risk of multivessel CAD was observed as per $1 \mathrm{mmHg}$ increased in brachial PP, measured at non-hypertension group $(\mathrm{OR}=1.04,95 \% \mathrm{CI}=1.01-1.07$, $P=0.0135)$ and hypertension group $(\mathrm{OR}=1.02,95 \% \mathrm{CI}=$ 1.01-1.03, $P=0.0037$ ), while a trend for patients with brachial $\mathrm{PP} \geq 60 \mathrm{mmHg}$, among non-hypertension group $(\mathrm{OR}=2.71, \quad 95 \% \quad \mathrm{CI}=0.94-5.03, \quad P=0.0706) \quad$ and

Table 1 Demographic Characteristics of the Patients ${ }^{a}$

\begin{tabular}{|c|c|c|c|c|c|}
\hline \multirow[t]{2}{*}{ Parameters } & \multirow{2}{*}{$\begin{array}{l}\text { Non-CAD } \\
n=280\end{array}$} & \multicolumn{3}{|l|}{ CAD } & \multirow[t]{2}{*}{$P$-value } \\
\hline & & One-vessel $(n=171)$ & Two-vessel $(n=87)$ & Three-vessel $(n=116)$ & \\
\hline Age, year & $61.68 \pm 10.11$ & $65.88 \pm 9.77$ & $66.76 \pm 7.42$ & $68.94 \pm 7.85$ & $<0.001$ \\
\hline Male, no. (\%) & $128(45.71)$ & 93 (54.39) & $53(60.92)$ & $77(66.38)$ & $<0.001$ \\
\hline $\mathrm{BMI}, \mathrm{kg} / \mathrm{m}^{2}$ & $24.16 \pm 3.30$ & $24.42 \pm 3.74$ & $24.35 \pm 2.81$ & $23.97 \pm 3.00$ & 0.679 \\
\hline Smoking, no. (\%) & $79(28.21)$ & $65(38.01)$ & $39(44.83)$ & $57(49.14)$ & $<0.001$ \\
\hline Diabetes, no. (\%) & $47(16.79)$ & $37(21.64)$ & $26(29.89)$ & $43(37.07)$ & $<0.001$ \\
\hline Hypercholesterolemia, no. (\%) & $89(31.79)$ & $64(37.43)$ & $40(45.98)$ & $49(42.24)$ & 0.054 \\
\hline $\mathrm{Cr}, \mu \mathrm{mol} / \mathrm{L}$ & $75.26 \pm 22.86$ & $79.16 \pm 24.12$ & $80.79 \pm 28.97$ & $93.29 \pm 52.38$ & $<0.001$ \\
\hline Hypertension, no. (\%) & $168(60.00)$ & $126(73.68)$ & $62(71.26)$ & $99(85.34)$ & $<0.001$ \\
\hline Systolic Pressure (mmHg) & $139.88 \pm 19.20$ & $145.32 \pm 23.45$ & $144.14 \pm 21.11$ & $150.97 \pm 25.79$ & $<0.001$ \\
\hline Diastolic Pressure $(\mathrm{mmHg})$ & $83.47 \pm 12.56$ & $83.50 \pm 11.98$ & $80.66 \pm 12.53$ & $81.59 \pm 12.17$ & 0.165 \\
\hline Pulse Pressure (mmHg) & $56.40 \pm 14.71$ & $61.82 \pm 20.16$ & $63.48 \pm 16.31$ & $69.37 \pm 20.43$ & $<0.001$ \\
\hline
\end{tabular}

aplus-minus values are means \pm SD. Percentages do not sum to 100 because of rounding $B M I$ Body mass index, CAD Coronary artery disease, $\mathrm{Cr}$ Creatinine 
Table 2 Association of brachial PP with the increased number of diseased vessels

\begin{tabular}{|c|c|c|c|c|c|c|c|c|}
\hline \multirow[t]{2}{*}{ Variables } & \multirow[t]{2}{*}{$\mathrm{n}$} & \multirow{2}{*}{$\begin{array}{l}\text { Mean } \pm \text { SD } \\
(\mathrm{mmHg})\end{array}$} & \multicolumn{3}{|c|}{ Crude } & \multicolumn{3}{|c|}{ Adjusted } \\
\hline & & & $\beta$ & SE & $P$ & $\bar{\beta}$ & SE & $P$ \\
\hline Brachial PP (per 1 mmHg) & 654 & $61.06 \pm 18.15$ & 0.01 & 0.00 & $<0.0001$ & 0.01 & 0.00 & $<0.0001$ \\
\hline Non-Hypertension & 199 & $52.27 \pm 14.37$ & 0.01 & 0.00 & 0.004 & 0.01 & 0.00 & 0.029 \\
\hline Hypertension & 455 & $64.91 \pm 18.30$ & 0.01 & 0.00 & $<0.0001$ & 0.01 & 0.00 & $<0.0001$ \\
\hline
\end{tabular}

Adjusted for: Age; Gender; BMI; Smoking; Diabetes; Hypercholesterolemia; $\mathrm{Cr}$

hypertension group $(\mathrm{OR}=1.51,95 \% \mathrm{CI}=0.97-2.35, P=$ 0.0660) (Table 4). Further dividing the hypertension group into isolated systolic hypertension and other types of hypertension, the risk of multivessel CAD were respectively $1.02(1.00,1.06)$ and $1.02(1.01,1.03)$ as per 1 $\mathrm{mmHg}$ increased in brachial PP. In addition, the association between increasing brachial PP and the increased risk of multivessel CAD was also observed in the subgroup of diabetes (Table 4).

\section{Discussion}

In this cross-sectional study, we explored the association between brachial PP and CAD in patients with stable angina. What we found was that increasing brachial PP was significantly and independently associated with increased risk of multivessel coronary disease. This association was more pronounced in hypertension group than in non-hypertension one.

Many studies have so far investigated the association between PP and CAD. Lee et al. [16] were the first to explore the association between high $\mathrm{PP}$ and the presence of CAD. PP was measured both by non-invasive sphygmomanometer and invasive catheterization before surgical intervention in 159 patients of mitral valve stenosis. PP was considered to be an independent predictor of CAD, although the contribution of age, gender and mean BP was profound. They reported an accuracy of $62 \%$ in having significant CAD in the presence of a wide PP. Millar et al. [17] performed a retrospective study of the MRC Mild Hypertension Trial. They concluded that PP was a strong risk factor for coronary events in untreated hypertensive male subjects. What' more, a study by Pařenica et al. [13] of 1075 consecutive stable male patients showed that increased aortic PP was independently associated with more severe atherosclerosis as assessed by the significant number of diseased coronary vessel.

Studies on the relationship between aortic PP and CAD are numerous, but few are directly examining brachial PP and CAD. Brachial PP, calculated by subtracting DBP from SBP, can be easily acquired without invasive equipment. As an easily available and non-invasive indicator, it can be better applied in clinical practice. Gatzka et al. [18] found that brachial PP was higher in patients with CAD than those without, which was consistent with our results. However, they only recruited 55 patients. Kim et al. [19] did a cross-sectional study of a register database, the Korean Women's Chest Pain Registry. They similarly found a higher level of brachial PP in patients with obstructive CAD than in those without. They went a step further by focusing on gender differences in the relationship between brachial PP and the extent of CAD. In our cross-sectional study, with a certain sample size, we further explored the relationship between brachial PP and CAD in the subgroups with or without hypertension. The association was pronounced in both groups. The statistical significance, however, is greater in hypertension group.

$\mathrm{PP}$, either measured in aortic or brachial artery, has shown a significant association with CAD. However, the jury is still out on the underlying mechanisms of the association between $\mathrm{PP}$ and CAD. In terms of hemodynamics, PP is largely determined by arterial stiffness, stroke volume and wave reflections [3]. Among them, arterial stiffness plays the most important role in the effects of an increased PP on the risk of CAD. Arterial stiffness reduces vascular compliance, causing increased SBP and decreased DBP. Increased SBP augments the cardiac load and oxygen consumption, while decreased DBP diminishes coronary perfusion leading to myocardial ischemia. Also, PP has been reported to be related to the endothelial vasomotor

Table 3 Association of brachial PP with Multivessel CAD

\begin{tabular}{|c|c|c|c|c|c|c|c|c|}
\hline \multirow[t]{2}{*}{ Varibales } & \multirow[t]{2}{*}{$\mathrm{n}$} & \multirow{2}{*}{$\begin{array}{l}\text { Mean } \pm \text { SD } \\
(\mathrm{mmHg})\end{array}$} & \multicolumn{3}{|c|}{ Crude } & \multicolumn{3}{|c|}{ Adjusted } \\
\hline & & & $\mathrm{OR}$ & $95 \% \mathrm{Cl}$ & $P$ value & $\overline{\mathrm{OR}}$ & $95 \% \mathrm{Cl}$ & $P$ value \\
\hline $\mathrm{PP}<60 \mathrm{mmHg}$ & 322 & $46.98 \pm 7.71$ & 1.00 & & & 1.00 & & \\
\hline$P P \geq 60 \mathrm{mmHg}$ & 332 & $74.71 \pm 14.57$ & 1.81 & $(1.27,2.58)$ & 0.0010 & 1.69 & $(1.14,2.48)$ & 0.0084 \\
\hline PP (per $1 \mathrm{mmHg}$ ) & 654 & $61.06 \pm 18.15$ & 1.02 & $(1.01,1.03)$ & $<0.0001$ & 1.02 & $(1.01,1.03)$ & 0.0002 \\
\hline
\end{tabular}

Adjusted for: Age; Gender; BMl; Smoking; Diabetes; Hypercholesterolemia; Cr; Multivessel CAD was defined as luminal stenosis $\geq 50 \%$ in two or more vessels 
Table 4 Subgroup analysis of association between brachial PP and Multivessel CAD

\begin{tabular}{|c|c|c|c|c|}
\hline Subgroups & $n$ & OR & $95 \% \mathrm{Cl}$ & $P$ value \\
\hline \multicolumn{5}{|l|}{ Hypertension } \\
\hline \multicolumn{5}{|l|}{ No } \\
\hline $\mathrm{PP}<60 \mathrm{mmHg}$ & 142 & 1.00 & & \\
\hline$P P \geq 60 \mathrm{mmHg}$ & 57 & 2.59 & $(1.27,5.26)$ & 0.0086 \\
\hline PP (per 1 mmHg) & 199 & 1.04 & $(1.01,1.06)$ & 0.0017 \\
\hline \multicolumn{5}{|l|}{ Yes } \\
\hline \multicolumn{5}{|l|}{ All } \\
\hline $\mathrm{PP}<60 \mathrm{mmHg}$ & 180 & 1.00 & & \\
\hline $\mathrm{PP} \geq 60 \mathrm{mmHg}$ & 275 & 1.62 & $(1.08,2.42)$ & 0.0195 \\
\hline PP (per 1 mmHg) & 455 & 1.02 & $(1.01,1.03)$ & 0.0007 \\
\hline \multicolumn{5}{|c|}{ Isolated systolic hypertension } \\
\hline PP (per 1 mmHg) & 111 & 1.02 & $(1.00,1.06)$ & 0.0089 \\
\hline \multicolumn{5}{|c|}{ Other types of hypertension } \\
\hline $\mathrm{PP}<60 \mathrm{mmHg}$ & 180 & 1.00 & & \\
\hline $\mathrm{PP} \geq 60 \mathrm{mmHg}$ & 164 & 1.44 & $(1.03,3.17)$ & 0.0279 \\
\hline PP (per 1 mmHg) & 344 & 1.02 & $(1.01,1.03)$ & 0.0010 \\
\hline \multicolumn{5}{|l|}{ Diabetes } \\
\hline \multicolumn{5}{|l|}{ No } \\
\hline $\mathrm{PP}<60 \mathrm{mmHg}$ & 336 & 1.00 & & \\
\hline $\mathrm{PP} \geq 60 \mathrm{mmHg}$ & 165 & 1.78 & $(1.07,2.49)$ & 0.0058 \\
\hline PP (per $1 \mathrm{mmHg}$ ) & 501 & 1.02 & $(1.01,1.03)$ & 0.0006 \\
\hline \multicolumn{5}{|l|}{ Yes } \\
\hline $\mathrm{PP}<60 \mathrm{mmHg}$ & 64 & 1.00 & & \\
\hline $\mathrm{PP} \geq 60 \mathrm{mmHg}$ & 89 & 1.87 & $(1.15,4.43)$ & 0.0134 \\
\hline PP (per 1 mmHg) & 153 & 1.03 & $(1.01,1.07)$ & 0.0015 \\
\hline
\end{tabular}

dysfunction in the conduit and resistance vessels in the coronary circulation [20]. These above changes in the coronary circulation may exacerbate the progression of CAD, which helps to explain the mechanisms of the association between PP and CAD. More research is needed to further confirm the mechanisms.

Although brachial PP has been reported to be associated with the risk of CAD, studies have also shown that brachial PP gives less indications on the severity of coronary atherosclerosis than aortic PP. However, as a non-invasive indicator, brachial PP can be easily acquired without invasive equipment, thus, can be more acceptable to patients and better applied in daily clinical practice. Brachial PP can not only help to identify high-risk CAD patients for early intervention, but also be applied to develop effective therapeutic strategies for these patients.

\section{Study limitations}

The limitations of our study are worth noting. First and foremost, the design of the study was cross-sectional.
However, whether there is a real causal relationship between brachial PP and CAD has not been confirmed. Secondly, the patients enrolled in our study were from a single center. The study subjects might not represent the whole population, affecting the generalization of the conclusion. What's more, the bias in data collection should not be ignored. The treatment of antihypertensive medications within 12 months was self-reported. And the definition of hypertension was depended on previous diagnoses and the two BP measurements taken during the study. Also, the bias regarding blood pressure measurements should not be ignored.

\section{Conclusion}

A positive relationship between brachial PP and the number of diseased coronary vessels was found in our study. Increasing brachial PP was significantly and independently associated with increased risk of multivessel coronary disease in the stable angina patients. The association was more pronounced in hypertension group than in non-hypertension one.

\section{Abbreviations}

CAD: Coronary artery disease; PP: Pulse pressure; SBP: Systolic blood pressure; DBP: Diastolic blood pressure; CAG: Coronary angiography; BP: Blood pressure; LVEF: Left ventricular ejection fraction; BMI: Body mass index; Cr: Creatinine; SD: Standard deviation; SE: Standard error; OR: Odds ratio; $\mathrm{Cl}$ : Confidence interval

\section{Acknowledgements}

We acknowledge that The Second Affiliated Hospital and Yuying Children's Hospital of Wenzhou Medical University for supporting the work of our study.

\section{Authors' contributions}

KT. J and J. L conceived and designed the research. J. L and YP. P performed the studies, participated in data collection, data processing, statistical analysis and drafted the manuscript. The authors read and approved the final manuscript.

\section{Funding}

This work was supported by the National Natural Science Foundation of China (No. 81573185).

\section{Availability of data and materials}

Data and materials are available from the corresponding author upon reasonable request.

\section{Ethics approval and consent to participate}

The study protocol was approved by the institutional review board of Wenzhou Medical University. Written informed consents from each patient enrolled were obtained.

Consent for publication

Not Applicable.

\section{Competing interests}

The authors declare that they have no competing interests.

Received: 12 January 2020 Accepted: 4 March 2020

Published online: 20 March 2020

\section{References}

1. Roth GA, Abate $\mathrm{D}$, Abate $\mathrm{KH}$, et al. Global, regional, and national age-sexspecific mortality for 282 causes of death in 195 countries and territories, 
1980-2017: a systematic analysis for the global burden of disease study 2017. Lancet. 2018;392:1736-88. https://doi.org/10.1016/s01406736(18)32203-7.

2. Lopez AD, Mathers CD, Ezzati M, et al. Global and regional burden of disease and risk factors, 2001: systematic analysis of population health data. Lancet. 2006;367:1747-57. https://doi.org/10.1016/s0140-6736(06)68770-9.

3. Safar ME, Levy BI, Struijker-Boudier H. Current perspectives on arterial stiffness and pulse pressure in hypertension and cardiovascular diseases. Circulation. 2003;107:2864-9. https://doi.org/10.1161/01.CIR.0000069826. 36125.B4.

4. Corona G, Mannucci E, Lotti F, et al. Pulse pressure, an index of arteria stiffness, is associated with androgen deficiency and impaired penile blood flow in men with ED. J Sex Med. 2009;6:285-93. https://doi.org/10.1111/j. 1743-6109.2008.01059.x.

5. Jankowski P, Czarnecka D. Pulse pressure, blood flow, and atherosclerosis. Am J Hypertens. 2012;25:1040-1. https://doi.org/10.1038/ajh.2012.117.

6. Bangalore S, Messerli FH, Franklin SS, et al. Pulse pressure and risk of cardiovascular outcomes in patients with hypertension and coronary artery disease: an INternational VErapamil SR-trandolapril STudy (INVEST) analysis. Eur Heart J. 2009;30:1395-401. https://doi.org/10.1093/eurheartj/ehp109.

7. Zakopoulos NA, Lekakis JP, Papamichael CM, et al. Pulse pressure in normotensives: a marker of cardiovascular disease. Am J Hypertens. 2001;14: 195-9. https://doi.org/10.1016/s0895-7061(00)01268-1.

8. Temelkova-Kurktschiev TS, Kurktschiev DP, Vladimirova-Kitova LG, et al. Pulse pressure is a strong predictor of cardiovascular risk: data of the risk factors in impaired glucose tolerance for atherosclerosis and diabetes and the Sofia metabolic syndrome studies. Folia Med (Plovdiv). 2009;51:34-41.

9. Chen G, Bliden KP, Chaudhary R, et al. Central aortic pulse pressure, thrombogenicity and cardiovascular risk. J Thromb Thrombolysis. 2017;44: 223-33. https://doi.org/10.1007/s11239-017-1524-y.

10. Philippe F, Chemaly E, Blacher J, et al. Aortic pulse pressure and extent of coronary artery disease in percutaneous transluminal coronary angioplasty candidates. Am J Hypertens. 2002;15:672-7. https://doi.org/10.1016/s08957061(02)02961-8.

11. Danchin N, Benetos A, Lopez-Sublet M, et al. Aortic pulse pressure is related to the presence and extent of coronary artery disease in men undergoing diagnostic coronary angiography: a multicenter study. Am J Hypertens. 2004;17:129-33. https://doi.org/10.1016/j.amjhyper.2003.09.010.

12. Guray Y, Guray U, Altay H, et al. Aortic pulse pressure and aortic pulsatility are associated with angiographic coronary artery disease in women. Blood Press. 2005;14:293-7. https://doi.org/10.1080/08037050500238568.

13. Pařenica J, Kala P, Jarkovský J, et al. Relationship between high aortic pulse pressure and extension of coronary atherosclerosis in males. Physiol Res. 2011;60:47-53. https://doi.org/10.33549/physiolres.931957.

14. Tallarida RJ, Murray RB. Chi-Square Test. In: Tallarida RJ, Murray RB, editors. Manual of Pharmacologic Calculations: With Computer Programs. New York: Springer New York; 1987. p. 140-2.

15. Rédei GP. Fisher's Exact Test. In: Encyclopedia of Genetics, Genomics, Proteomics and Informatics. Dordrecht: Springer Netherlands; 2008. p. 690.

16. Lee TM, Lin YJ, Su SF, et al. Relation of systemic arterial pulse pressure to coronary atherosclerosis in patients with mitral stenosis. Am J Cardiol. 1997; 80:1035-9. https://doi.org/10.1016/s0002-9149(97)00599-7.

17. Millar JA, Lever AF, Burke $V$. Pulse pressure as a risk factor for cardiovascular events in the MRC mild hypertension trial. J Hypertens. 1999;17:1065-72. https://doi.org/10.1097/00004872-199917080-00004.

18. Gatzka CD, Cameron JD, Kingwell BA, et al. Relation between coronary artery disease, aortic stiffness, and left ventricular structure in a population sample. Hypertension. 1998;32:575-8. https://doi.org/10.1161/01.hyp.32.3.575.

19. Kim H-L, Kim M-A, Shim W-J, et al. Sex difference in the association between brachial pulse pressure and coronary artery disease: the Korean Women's chest pain registry (KoROSE). J Clin Hypertens (Greenwich). 2017; 19:38-44. https://doi.org/10.1111/jch.12862.

20. Ichigi $Y$, Takano $\mathrm{H}$, Umetani $\mathrm{K}$, et al. Increased ambulatory pulse pressure is a strong risk factor for coronary endothelial vasomotor dysfunction. J Am Coll Cardiol. 2005;45:1461-6. https://doi.org/10.1016/j.jacc.2005.01.038.

\section{Publisher's Note}

Springer Nature remains neutral with regard to jurisdictional claims in published maps and institutional affiliations.

\section{Ready to submit your research? Choose BMC and benefit from}

- fast, convenient online submission

- thorough peer review by experienced researchers in your field

- rapid publication on acceptance

- support for research data, including large and complex data types

- gold Open Access which fosters wider collaboration and increased citations

- maximum visibility for your research: over $100 \mathrm{M}$ website views per year

At BMC, research is always in progress.

Learn more biomedcentral.com/submissions 